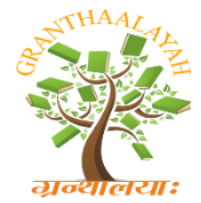
INTERNATIONAL JOURNAL OF RESEARCH - GRANTHAALAYAH A knowledge Repository

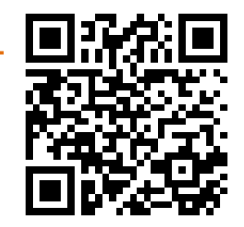

Management

\title{
AADHAAR ENABLED PAYMENT SYSTEM - A NEW INNOVATION TO DIGITAL PAYMENTS OF INDIA
}

\author{
Kamila Sharmin. I ${ }^{* 1}$ \\ ${ }^{* 1}$ B.com (General), Shri Krishnaswamy College for Women, India
}

\begin{abstract}
Aadhaar enabled payment system (AEPS) is a type of payment system that is based on the unique identification number and allows Aadhaar card holder seamlessly make financial transaction through Aadhaar based authentication. The AEPS framework expects to enable all the areas of society by making monetary and banking administrations accessible to all the Aadhaar. AEPS is context through one can make fund transfer, make disbursement, make cash deposit, make extractions, make request for information about bank balance etc.
\end{abstract}

Keywords: Business Correspondents (BCs); National Rural Employment Guarantee Act (NREGA); Issuer Identification Number (IIN); Unique Identification Authority of India (UIDAI).

Cite This Article: Kamila Sharmin. I. (2020). "AADHAAR ENABLED PAYMENT SYSTEM A NEW INNOVATION TO DIGITAL PAYMENTS OF INDIA." International Journal of Research - Granthaalayah, 8(4), 67-71. https://doi.org/10.29121/granthaalayah.v8.i4.2020.8.

\section{Introduction}

Aadhaar Enabled Payment System or AEPS is another payment management presented by the National Payments Corporation of India to banks and money related foundations utilizing 'Aadhaar'. Aadhaar is a special distinguishing proof number gave by Unique Identification Authority of India (UIDAI). This administration can be profited at Customer Access Points (CSPs) oversaw by Business Correspondents (BCs) utilizing Point of Sale (POS) gadgets. AEPS benefits across India through its delegated BCs who use Micro ATM, PoS machines.

An AEPS is a bank determined model which licenses online interoperable cash related thought trade at PoS (Micro ATM) through the Business correspondent of any bank using the Aadhaar validation. AEPS licenses you to finish six sorts of trades. This organization draws in a bank customer to use Aadhaar as his/her character to get to his/her individual Aadhaar engaged money related adjust and perform crucial intrabank or interbank trades, including - checking balance, depositing cash, Withdrawal of cash and Settlements. For all trades whether intrabank or interbank, a Operation Receipt in print and offered over to the customer as a trade record with its remission status, by the $\mathrm{BC}$ through whom the trade was begun. A Business Correspondent who is an arbiter chosen by a bank to extend Banking organizations in zones where they don't have a branch can 
guarantee Micro ATM to offer AEPS organizations to bank customers. The degree of activities grasped by the Business Correspondents joins, cash withdrawals and interbank repayments. The principle data sources required for a customer to do a trade under this circumstance are: -

- IIN (Identifying the Bank to which the customer is connected)

- Aadhaar Number

- Unique mark caught during their selection

\section{Targets}

- To connect with a customer to use Aadhaar by way of his/her character to get to individual Aadhaar engaged record and perform essential monetary trades like cash store, cash withdrawal, Intrabank or interbank fund move, balance enquiry and get a little verbalization through a Business Correspondent

- To perform the goal line of Reserve Bank of India (RBI) and Government of India (GoI) in progressing Monetary Insertion.

- To perform the goal line of RBI in electrifying of retail portions.

- To engage banks to course the Aadhaar began interbank trades through a central trading and clearance office.

- To energize installment of Government benefits like NREGA, Social Security benefits, Handicapped Old Age Annuity, etc. of any Central or State Government frames, using Aadhaar and confirmation thereof as maintained by UIDAI.

- To empower between operability across banks in a sheltered and ensured about way.

- To accumulate the foundation for a full extent of Aadhaar enabled Banking organizations.

\section{Issuer Identification Number - IIN}

1) Distinguishing proof Number (IIN) for alluding to the bank in all his/her AEPS Transactions. The IIN will be a six-digit number which will be assigned to a bank upon an application to NPCI from the Bank looking for IIN for AEPS. A Bank offering AEPS will prompt an Aadhaar empowered financial balance holder its original Issuer.

2) The Aadhaar number of the recipient would be joined by the IIN of the Beneficiary's Bank. In this manner the contribution for interestingly alluding to the recipient's (or the goal) record would be IIN plus Aadhaar number

3) IIN combined with Aadhaar number will remarkably connection to an Aadhaar empowered financial balance with that Bank. On the other hand, rather than entering the digits for IIN, it might be spoken to at the Micro ATM level by the particular banks' name/logo, which might be chosen from a drop-down menu. This would make the client experience more extravagant.

\section{Business Correspondent}

A Business Correspondent is an intermediary used by a bank to extend Banking services in areas where they do not have a branch. The choice of activities undertaken by the Business Correspondents includes, collection of minor value deposits, Cash extractions and minor value interbank settlements. Within the possibility of AEPS, a BC of a bank is treated as a vital part of the Bank that it resembles with. 


\section{Intrabank (On-us) and Interbank (Off-us) Transactions}

An intrabank (On-us) exchange is one where an Aadhaar started exchange has impacts just in accounts inside very much the same Bank and doesn't require an interbank settlement.

An interbank (Off-us) exchange is one where there is development of assets starting with one Bank then onto the next requiring an interbank settlement.

\section{Mechanism}

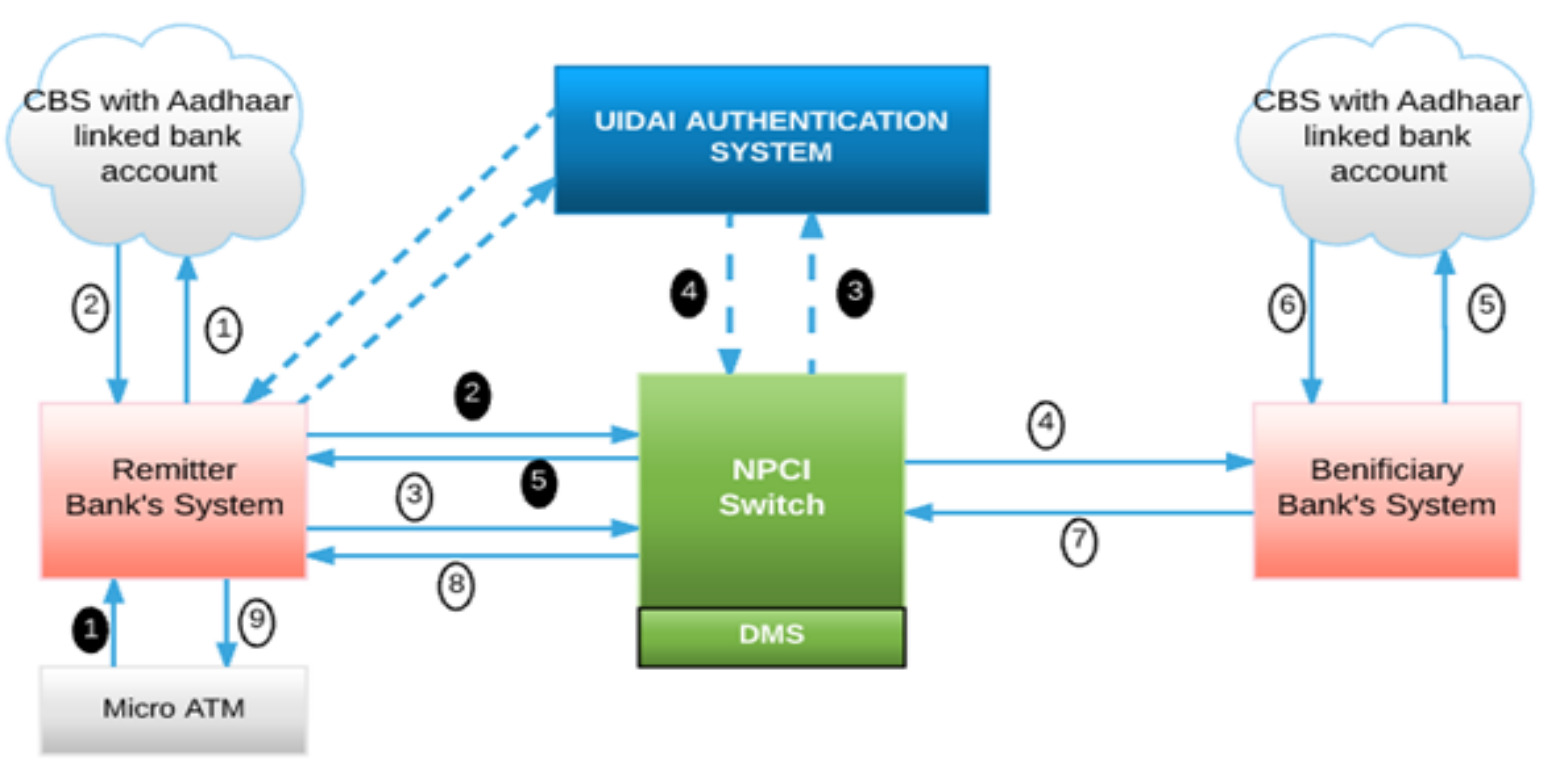

In any normal Aadhaar to Aadhaar reserves move, there would be six gatherings:

1) A Customer starting an exchange through a BC.

2) Dispatching Bank's switch

3) NPCI - AEPS Switch

4) UIDAI Authentication

5) Recipient Bank's Switch

6) A Beneficiary getting to his record through a $\mathrm{BC}$

The four Aadhaar empowered essential sorts of banking exchanges are as per the following: -

- Cash Withdrawal

- Cash Deposit

- Aadhaar to Aadhaar Funds Transfer

- Balance Enquiry

\section{Cash Withdrawal Through A Business Correspondent}

A Bank client would make a Cash withdrawal through the Micro ATM of a BC. The money withdrawal exchange first streams to the Correspondent Bank of the BC. On the off chance that the exchange is intra-bank, on productive Aadhaar Substantiation, the bank will charge the client's record and send its positive reaction to the Micro ATM. On the off chance that it is interbank, the 
exchange will be sent to the Issuer Bank through NPCI's switch. On fruitful Aadhaar Authentication, the Issuer Bank will charge the Aadhaar empowered record of the client and send its positive reaction to the Micro ATM of the BC through the NPCI switch. Regardless of whether intrabank or interbank, simply after receipt of a positive reaction, money will be apportioned.

In the event that the reaction from the Issuer bank isn't gotten inside a set time limit, the guarantor bank will get inversion warning from anybody of NPCI switch or the Acquirer Bank or the Micro ATM relying on who got the reaction coordinated out. No cash will be apportioned to the starting client by $\mathrm{BC}$; it is be that as it may, fitting that the $\mathrm{BC}$ starts a parity enquiry before sending an inversion warning to the backer if a break reaction is gotten by it.

\section{Cash Deposit Through A Business Correspondent}

A Bank Customer would make a Deposit cash through a BC who utilizes a Micro ATM terminal. A money store exchange started by a $\mathrm{BC}$ first streams to the Correspondent Bank of the BC. On the off chance that the exchange is intra-bank, on effective Aadhaar Authentication, the bank will credit the client's record and send a positive reaction to the Micro ATM. In the event that it is between bank, the exchange will be sent to NPCI's switch for ahead accommodation to the Issuer Bank. On fruitful Aadhaar Authentication, the Issuer bank will credit the client's Aadhaar empowered record and send its reaction to the Micro ATM that started the exchange, through NPCI switch, for having credited the record.

In the event that the reaction from the Issuer bank isn't gotten inside a set time limit, the guarantor bank will get an inversion notice from anybody of NPCI switch or the Acquirer Bank or the Micro ATM relying on who got the reaction planned out. The $\mathrm{BC}$ would, right now, the money to the dispatching client. Nonetheless, it is prudent that the BC sends a Balance enquiry to guarantee that the credit for the money store has not been affected in the goal account before restoring the money.

\section{Aadhaar to Aadhaar Interbank Funds Transfer}

In the underlying period of AEPS execution, an Aadhaar to Aadhaar reserves move can't be a gained exchange. The Remitting client ought to essentially have his/her Aadhaar empowered Account with the Remitting Bank and the exchange will be affected simply after a fruitful charge to this record. A Remitting Customer is required to start an Aadhaar empowered bury Bank settlement just from the Micro ATM of a Bank with whom he/she is holding an Aadhaar empowered Account.

At the point when a Funds Transfer exchange is started from a Micro ATM of a BC, the Remitting Bank initially, gets the exchange Aadhaar validated. Upon effective Aadhaar Authentication, the bank charges the Aadhaar empowered record of the starting client with the settlement sum and sends a Payment Request to the Beneficiary's Bank dependent on the IIN gave, through the NPCI Switch. Recipient's Bank would credit the Beneficiary's Aadhaar empowered record and forward its positive reaction to the Micro ATM that started the solicitation, through NPCI switch. The client will know the absolution of the settlement from the Transaction Receipt.

On the off chance that the reaction from the recipient's bank isn't gotten inside a set time limit, no inversion notices from NPCI switch or the Acquirer Bank or the Micro ATM will be sent to the 
recipient's Bank. For all interbank settlements that have planned out, Banks are encouraged to utilize the Dispute Management System alluded to in this to determine interbank settlement issues.

\section{Aadhaar Initiated Balance Enquiry}

Parity Enquiry is a non-budgetary exchange. An equalization enquiry might be on-us or off-us. In the event that it is On-Us, the bank upon a fruitful Aadhaar Authentication, exhorts the parity in the client's record to the Micro ATM that started the Inquiry. On the off chance that it is off-us, an equalization solicitation will be sent to the backer Bank through NPCI. Upon fruitful Aadhaar Authentication, the Balance exhortation got from the Issuer bank will be sent to Micro ATM that started the Inquiry, through NPCI switch.

\section{Conclusion}

Dynamically the financial service esteem chain is getting disaggregated and fresher particular members are entering the scene, for example BCs, innovation specialist co-ops, and so forth., which has prompted generous reduction in cost of administration conveyance. Still there are numerous difficulties that banks face in offering money related administrations to poor people, particularly in the remote areas. High last mile cost and mechanical constraints, alongside lowincome capability of these clients, brings about budgetary overhauling offering to the greater part of them holding a restricted/no benefit potential for banks. Monetary assistance is one of the most significant necessities for the as of now barred portion in such manner, UIDAI accepts that the arrangement of giving Aadhaar numbers to the expected 60 crore inhabitants throughout the following 4 years and setting up an online biometric verification administration will help address a considerable lot of the present difficulties looked by the banks in conveyance of money related administrations. During enrolment in a specific locale, UIDAI plans to issue Aadhaar to all the inhabitants of that area and therefore opening record during Aadhaar enrolment offers a novel chance to accomplish unequaled client scale at no/insignificant expense for banks. This would be hugely gainful for banks as it would significantly diminish the normal foundation/conveyance cost of serving these clients. The banks can tap the dormant interest for reserve funds, settlement and other monetary items like advances and protection by putting resources into making a complimentary assistance conveyance arrange and along these lines even the negligible clients would get productive for the banks to serve.

\section{References}

[1] https://www.bankbazaar.com

[2] https://www.npci.org.in

[3] https://www.cashlessindia.gov.in

[4] https://www.myoxigen.com

[5] https://www.paisabazaar.com

*Corresponding author.

E-mail address: Kamilasharmin786@, gmail.com 